\title{
Terapia Ocupacional y desplazamiento humano forzado Colombia, febrero de $2012^{1}$
}

\author{
Adriana Caballero ${ }^{2}$ \\ Aleida Fernández-Moreno ${ }^{3}$ \\ Solángel García-Ruiz ${ }^{4}$ \\ Aida Navas ${ }^{5}$ \\ Maribel Moreno-Sosa ${ }^{6}$
}

Caballero, A., Fernandez-Moreno, A., García-Ruíz, S., Navas, A., Moreno-Sosa, M. (2018). Terapia Ocupacional y desplazamiento humano forzado. Colombia, febrero de 2012. Revista Ocupación Humana, 18(1), 65-70.

(Documento original difundido en 2012 por el CCTO).

El siguiente es un documento preparado por profesionales miembros del Colegio Colombiano de Terapia Ocupacional, con el fin de atender la convocatoria de la Federación Mundial de Terapeutas Ocupacionales -WFOT para aportar a la elaboración de posición de Terapia Ocupacional frente al desplazamiento humano en el mundo.

\footnotetext{
1 Este documento fue enviado a la WFOT y divulgado al interior del Colegio Colombiano de Terapia Ocupacional en el año 2012; para su publicación en este número como documento histórico, se introdujeron correcciones mínimas de estilo respecto a la versión original, los datos de identificación de las autoras corresponden al año 2012. La discusión y construcción alrededor de los conceptos y propuestas que en su momento se plantearon resulta pertinente, pues en la actualidad el desplazamiento forzado sigue siendo un problema de grandes dimensiones en Colombia. Los datos estadísticos de 2012 han sido superados de manera importante por causa del conflicto armado y de las condiciones que persisten en algunos territorios, no obstante el importante resultado para Colombia que se deriva de la firma del Acuerdo de Paz con las FARC y el proceso que actualmente adelanta el Gobierno Nacional con el ELN.

${ }^{2}$ Terapeuta Ocupacional. Magíster en Sociología. Defensoría del Pueblo. Bogotá, Colombia. accaballerop@gmail.com

${ }^{3}$ Terapeuta Ocupacional. Magíster en Desarrollo Educativo y Social. Doctora en Ciencias Sociales, niñez y juventud. Directora Maestría en Discapacidad e Inclusión Social, profesora Departamento de la Ocupación Humana, Universidad Nacional de Colombia. cafernandezm@unal.edu.co iD https://orcid.org/0000-0003-2937-9598

${ }^{4}$ Terapeuta Ocupacional. Especialista en Seguridad Social. Magíster en Desarrollo Educativo y Social. Consultora, Organización Panamericana de Salud. Profesional especializada, Secretaría Distrital de Salud de Bogotá. solecita_co@yahoo.com (iD) https://orcid.org/0000-0003-4976-9825

${ }^{5}$ Terapeuta Ocupacional. Certificada en Integración Sensorial. Presidenta Colegio Colombiano de Terapia Ocupacional. aidanavas2001@yahoo.com iD https://orcid.org/0000-0003-0238-635X

${ }^{6}$ Terapeuta Ocupacional. Especialista en Planeación, Control y Gestión del Desarrollo Social Especialista en Acción sin Daño y Construcción de Paz. demi68@hotmail.com

(iD) https://orcid.org/0000-0002-5286-9395
} 


\section{Definición}

De acuerdo con los "Principios rectores de los desplazamientos internos" (Consejo Económico y Social de las Naciones Unidas, 1998),

se entiende por desplazadas internas las personas o grupos de personas que se han visto forzadas u obligadas a escapar o huir de su hogar o de su lugar de residencia habitual, en particular como resultado o para evitar los efectos de un conflicto armado, de situaciones de violencia generalizada, de violaciones de los derechos humanos o de catástrofes naturales o provocadas por el ser humano, y que no han cruzado una frontera estatal internacionalmente reconocida. (p.5)

\section{Datos estadísticos, de ley y disposiciones constitucionales}

En Colombia, según el Departamento para la Prosperidad Social, que administra el Sistema de Información para la Población Desplazada -SIPOD, a 30 de noviembre de 2011 existen 3.875.087 personas víctimas de desplazamiento forzado, oficialmente registradas. De estas, 1.443.769 son menores de 18 años, 977.955 son mujeres y 251.440 pertenecen a alguna minoría étnica del país. De igual forma, los reportes oficiales señalan que del total de las y los colombianos en desplazamiento, al menos el $2.6 \%$ presenta alguna situación de discapacidad, principalmente de tipo cognitivo, categorizada en el SIPOD como "dificultades para pensar y memorizar". Por su parte, fuentes no gubernamentales, como la Consultoría para los Derechos Humanos y el Desplazamiento -CODHES, en el año 2011, han señalado que aproximadamente cinco millo- nes de personas se encuentran en situación de desplazamiento forzado, cifra significativamente superior a la oficial.

En reconocimiento a este marcado impacto cuantitativo del desplazamiento forzado en la población colombiana, en el año 2004 la Corte Constitucional declaró, mediante la Sentencia T-025 (Corte Constitucional de Colombia, 2004), a la situación en la que se encuentra la población internamente desplazada en el país, como un "estado de cosas inconstitucional", haciendo público para el Estado, la sociedad colombiana y la comunidad internacional que la población en desplazamiento se encuentra en condiciones intolerables desde el punto de vista constitucional, que están además en contradicción con el sentido del Estado Social de Derecho y con el deber de solidaridad bajo el cual debe actuar la sociedad.

Esta declaración constató que la violación de derechos humanos a la población en desplazamiento había ocurrido de manera masiva, prolongada y reiterada, y que no era imputable a una única autoridad, sino que obedecía a un problema estructural que afectaba a toda la política de atención diseñada por el Estado, a partir de la Ley 387 de 1997, "por la cual se adoptan medidas para la prevención del desplazamiento forzado; la atención, protección, consolidación y estabilización socioeconómica de los desplazados internos por la violencia" (Congreso de Colombia, 1997), en razón a la insuficiencia de recursos destinados a financiar dicha política y a la precaria capacidad institucional para implementarla.

Al respecto, la Corte consideró que las víctimas del desplazamiento forza- 
do, en términos generales, tenían derecho a recibir de forma urgente un trato preferente por parte del Estado, al restablecimiento de sus derechos, a recibir una atención integral sostenible y a que las medidas adoptadas tuvieran un carácter diferencial.

\section{El desplazamiento forzado y el desempeño ocupacional}

Según Moreno (2010), los impactos ocasionados al desempeño ocupacio$\mathrm{nal}^{7}$ en las víctimas del conflicto armado, como las personas en situación de desplazamiento forzado, pueden contemplar (figura 1):
Es frente a estos impactos donde corresponde a los procesos de reparación generar respuestas acordes, sensibles y fundamentadas, tales como "recibir resarcimiento por el daño que le fue infligido; buscando restablecer, en lo posible, la situación anterior a la comisión de los hechos, mejorar las condiciones de vida de las víctimas y promover reformas que impidan la repetición de los crímenes" (Fundación Ideas para la Paz, 2006). Es allí donde se plantea la inquietud sobre la pertinencia de las acciones desde Terapia Ocupacional, para involucrar las ocupaciones dignas dentro de los proyectos de vida de las personas que están reclamando un justo proceso.

Figura 1. El desplazamiento forzado y el desempeño ocupacional
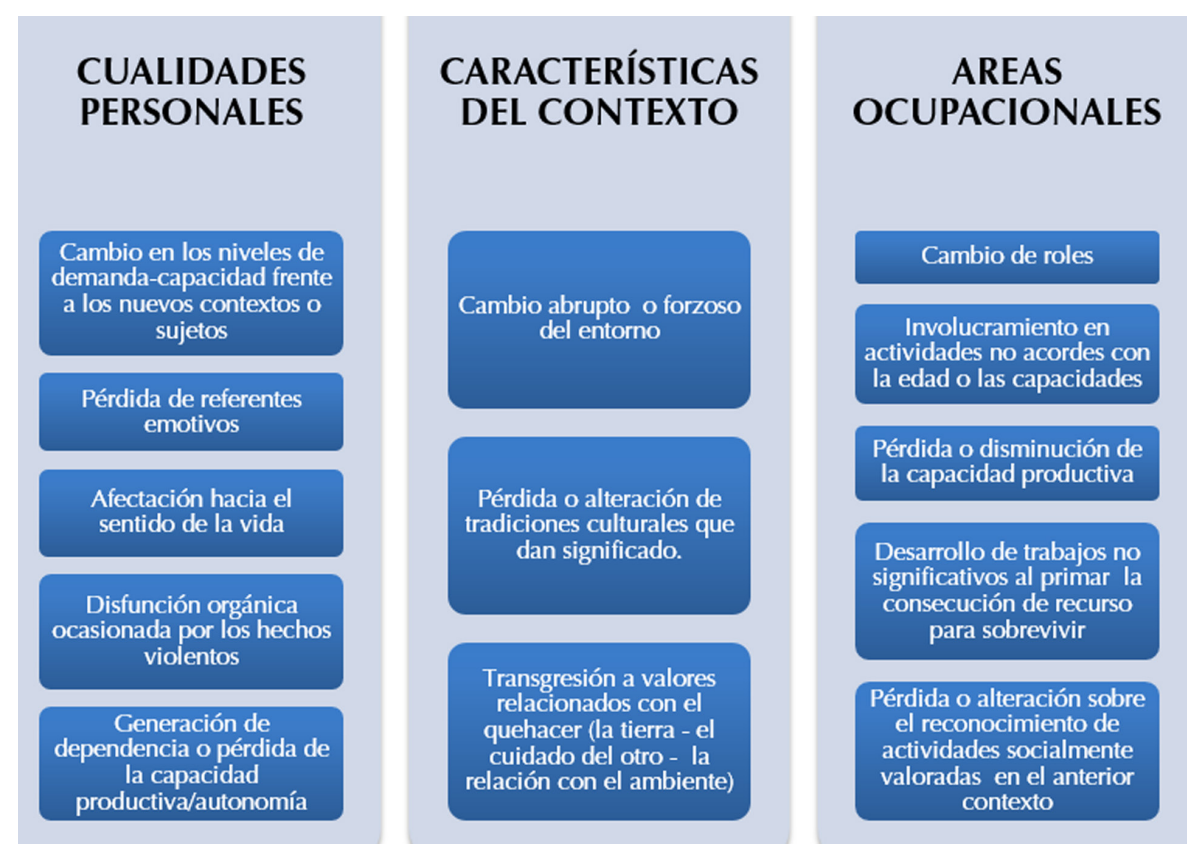

Fuente: Moreno, 2010.

\footnotetext{
7 “El desempeño ocupacional es el actuar ocupacional de las personas en ambientes específicos; es el proceso durante el cual la persona se motiva, inicia y completa distintas ocupaciones; es una trayectoria individual en la que intervienen las capacidades personales; las exigencias ocupacionales y las demandas del medio ambiente." (Trujillo, 2002, p.73)
} 


\section{Terapia Ocupacional y el desplazamiento forzado}

Para obtener una comprensión completa de la situación generada en el desplazamiento forzado y la propuesta de acción desde Terapia ocupacional, esta debe basarse en el principio fundamental de la reparación integral, la noción de "ocuparse de sí mismo".

Las acciones se orientan hacia los siguientes tópicos:

- Al reconocimiento de las víctimas del desplazamiento como sujetos de derechos, con capacidades plenas para la participación, la decisión y la reflexión. De tal manera que el sujeto tenga la oportunidad de participar y vivenciar las condiciones para "sentirse parte de", ser importante para su comunidad y expresar lo que quiere, es decir, participar, una de cuyas máximas expresiones está en el ámbito político y ocupacional.

- A la construcción conceptual y de análisis, para superar una dimensión netamente jurídica del derecho a la reparación integral de las víctimas de graves violaciones a sus derechos humanos; por ejemplo: en los procesos de planeación e investigación, para levantar el inventario de daños y potencialidades de las víctimas, se sugiere incorporar instrumentos de valoración propios de la profesión (como la historia ocupacional, los inventarios de intereses y roles, entre otros), que aportarían a la visión humanista.

- En la reconstrucción de la memoria ocupacional que permita recuperar las ocupaciones de las víctimas, aportando a la contextualización de los procesos productivos para que impacten positivamente y mantengan las tradiciones culturales propias de las comunidades a las que se pertenece, según los roles que desempeñan o desempeñaron y sus edades; aspectos estos fundamentales para el fortalecimiento de lazos y la identificación de recursos propios que contribuyan en la comunidad receptora. Este ejercicio puede nutrir el mapa de divisores y conectores frente al planteamiento y diseño de proyectos, de tal forma que permita salir del círculo de frustraciones que se generan en la utilización de recursos y tiempos que no funcionan.

- En la confluencia de las diferentes áreas de desarrollo que la Terapia Ocupacional plantea, proponiendo objetivos que armónicamente aboguen por el fortalecimiento psicosocial, mental, físico y espiritual en los diferentes entornos de desempeño, en ocupaciones tales como el trabajo, el estudio, el juego, el ocio y el autocuidado.

- Si estos procesos se dan en nuevos contextos, cuando el retorno no es una posibilidad, las acciones requieren incluir a los agentes culturales, sociales e institucionales con quienes interactúan las personas, en el ánimo de fortalecer desempeños y estructurar redes de apoyo.

- Al reconocimiento de situaciones particulares como la discapacidad, y de grupos poblacionales con características específicas como las mujeres y la niñez. 
- Si bien el componente productivo es vital, pensar en el papel que el ocio juega en el fortalecimiento de lazos sociales abre campos complementarios desde lo psicosocial para estos procesos, al ser un medio cotidiano que se puede utilizar para el fortalecimiento de la confianza, de las rutinas y del afianzamiento de prácticas culturales propias.

- Para la atención a la niñez y la juventud, la Terapia Ocupacional cuenta con las competencias del saber necesarias para generar propuestas que contrarresten las causas principales de la deserción escolar por parte de la población desplazada en los entornos receptores, tales como la explotación laboral, los impactos físicos y psicológicos derivados del evento mismo del desplazamiento, el maltrato y la discriminación en el ámbito escolar, el bajo rendimiento académico y las altas tasas de repitencia, la alta incidencia de casos de extraedad sin el acompañamiento requerido y los altos patrones de embarazo adolescente.

En síntesis, la Terapia ocupacional, en materia de programas de capacitación laboral y de generación de ingresos, debe tener un papel importante referido a la provisión de servicios dirigidos a la orientación ocupacional de los sujetos, entendiendo que dicha orientación tiene por objetivo promover la autonomía, socialización, productividad y realización personal, a través de la evaluación de las capacidades, intereses y formación adquirida por el individuo, para identificar el perfil ocupacional hacia la escogencia de los programas de formación laboral y reducir riesgos en los planes de in- versión de los capitales que se asignen a las personas para la generación de ideas productivas.

De igual forma, la Terapia Ocupacional puede generar aportes conceptuales y de análisis para superar una dimensión netamente jurídica del derecho a la reparación integral de las víctimas de graves violaciones a sus derechos humanos, como son las personas en desplazamiento forzado, extendiendo la mirada de las medidas de restitución e indemnización, mediante procesos de intervención centrados en la participación ocupacional del sujeto, el restablecimiento de su tejido social y la recuperación de la confianza en sí mismo y en la institucionalidad que representa el Estado.

\section{Referencias}

Congreso de Colombia. (1997, 18 de julio). Ley 387 de 1997. Por la cual se adoptan medidas para la prevención del desplazamiento forzado; la atención, protección, consolidación y esta estabilización socioeconómica de los desplazados internos por la violencia en la República de Colombia. Recuperado de http://www.alcaldiabogota.gov.co/ sisjur/normas/Norma1.jsp?i=340

Consejo Económico y Social de las Naciones Unidas. (1998). Principios rectores de los desplazamientos internos. En: Comisión de Derechos Humanos, $54^{\circ}$ periodo de sesiones, Intensificación de la promoción y el fomento de los derechos humanos y las libertades fundamentales, en particular la cuestión del programa y los métodos de trabajo de la comisión, derechos humanos, éxodos en masa y personas desplazadas (E/CN.4/1998/53/ 
Add.2) (pp. 5-14). Recuperado de http:// www.acnur.org/fileadmin/Documentos/ BDL/2001/0022.pdf?file=fileadmin/Documentos/BDL/2001/0022

Corte Constitucional de Colombia. (2004). Sentencia T-025 de 2004. Magistrado M. Cepeda. Bogotá, Colombia.

Fundación Ideas para la paz. (2006). La estabilización económica de la población desplazada. Bogotá: Serie working papers FIP No.3.

\section{Otras fuentes consultadas}

Beristain, C. (2008). Diálogos sobre la reparación. Experiencias en el Sistema Interamericano de Derechos Humanos. San José de Costa Rica: Instituto Interamericano de Derechos Humanos.

Borja, J., \& Muxí, Z. (2000). El espacio público, ciudad y ciudadanía. Barcelona: Diputación Provincial de Barcelona.

Caballero, A. (2011). La infantilización de la niñez en desplazamiento y su derecho a la reparación integral (Tesis de maestría). Universidad Nacional de Colombia, Bogotá.

Jiménez, C. (2010). El campo psicosocial: conceptos e implicaciones. En C. Díaz, Tareas pendientes:propuestas para la formulación de políticas públicas de reparación en Colombia (pp. 98-170). Bogotá: Centro Internacional de Justicia Transicional -ICTJ.
Moreno, M. (2010). Contribución de terapia ocupacional en los procesos de reparación al proyecto de vida de las víctimas del conflicto armado bajo el enfoque de ASD (Trabajo de grado de especialización). Universidad Nacional de Colombia, Bogotá.

Trujillo, A. (2002). Terapia ocupacional. Conocimiento y práctica en Colombia. Bogotá: Editorial Universidad Nacional de Colombia.

Parsons, T. (1971). El sistema de las sociedades modernas. Mexico: Trillas.

Pérez, L. E. (2010). Beneficios educativos como medida de reparación para víctimas de desplazamiento forzado. En C. Díaz, Tareas pendientes: propuestas para la formulación de políticas públicas de reparación en Colombia (pp. 4996). Bogotá: Centro Internacional para la Justicia Transicional -ICTJ. 